\author{
U.S. DEPARTMENT OF HEALTH, EDUCATION, AND WELFARE \\ CENTER FOR DISEASE CONTROL \\ NATIONAL INSTITUTE FOR OCCUPATIONAL SAFETY AND HEALTH \\ CINCINNATI, OHIO 45202 \\ HEALTH HAZARD EVALUATION DETERMINATION \\ REPORT NO. 78-21-539 \\ CHAMPION BUILDING PRODUCTS \\ BONNER, MONTANA \\ NOVEMBER 1978
}

1. TOXICITY DETERMINATION

It has been determined that veneer dryer emrissions including abietic and pimaric acids and $\alpha$ - and B-pinine may produce some subjective upper respiratory and eye irritation, but based on the medical testing performed at the Champion Building Products, Bonner, Montana, there was no adverse effect on the mean puTmonary functions of the group studied between the pre- and post- shift tests.

This conclusion is based on statistical comparisons of the pre-shift and post-shift pulmonary function parameters. The four parameters of pulmonary function assessed were: (1) forced vital capacity (FVC), (2) forced expiratory volume in the first second of exhalation $\left(F E V_{1}\right)$, (3) the ratio of FEV J/FVC to determine the percentage of the FVC expelled in the first second, and (4) the forced expiratory flow during the mid fifty percent of exhalation (FEF 25-75). Environmental levels slightly exceeded leveis found in all other plywood facilities that have been evaluated by the National Institute for Occupational Safety and Health. Concentrations with the range and mean for the four plants studied are given below. $6,7,8$

$$
\alpha \text { - and } \beta-\text { pinene }\left(\mathrm{mg} / \mathrm{m}^{3}\right)
$$

$\begin{array}{lll} & \text { Range } & \text { Mean } \\ \text { Plant 1 } & 0.11-5.0 & 0.73 \\ \text { Plant 2 } & 0.22-11.0 & 3.5 \\ \text { Plant 3 } & 0.40-3.3 & 1.4 \\ \text { Plant 4 } & 0.55-14.1 & 5.0\end{array}$

total organic acid $\left(\mathrm{mg} / \mathrm{m}^{3}\right)$

\begin{tabular}{ll} 
Range & Mean \\
\hline $0.01-0.60$ & 0.21 \\
$0.02-1.2$ & 0.21 \\
$0.004-0.15$ & 0.07 \\
$0.01-2.6$ & 0.79
\end{tabular}

Only a long-term survey with periodic (annual) pulmonary function testing would evaluate this matter completely. There is no evidence from this study to suggest that veneer dryer emissions cause allergic pulmonary disease or hay fever. This determination is based upon a thorough inspection of the veneer dryer operations, environmental measurements, medical interviews and physical examinations, and pulmonary function tests. 
Health Hazard Evaluation

Report No. 78-21, Page 2

Detailed information concerning medical and environmental results of the determination are contained in the body of this report. Recommendations are included which are designed to keep the employee exposure to plywood veneer dryer emissions to a minimum.

II. DISTRIBUTION AND AVAILABILITY

Copies of this determination report are currently available upon request from the National Institute for Occupational Safety and Health (NIOSH), Division of Technical Services, Information Resources and Dissemination Section, 4676 Columbia Parkway, Cincinnati, Ohio 45226. After 90 days the report will be available through the National Technical Information Service (NTIS), Springfield, Virginia. Information regarding its availability through NTIS can be obtained from NIOSH, Publications Office, at the Cincinnati address.

Copies of this report have been sent to:

1. Champion Building Products, Bonner, Montana

2. Lumber and Sawmi11 Workers L.P.I.W. Local Union 3038, Missoula, Montana

3. U.S. Department of Labor/OSHA - Region VIII

4. NIOSH - Region VIII.

For the purpose of informing 475 affected workers, a copy of this report shall be posted in a prominent place accessible to the employees for a period of 30 calendar days.

III. INTRODUCTION

Section 20(a)(6) of the Occupational Safety and Health Act of 1970, 29 U.S.C. 669 (a) (6), authorizes the Secretary of Health, Education, and Welfare, following a written request by any employer or authorized representative of employees, to determine whether any substance normally found in the place of employment has potentially toxic effects in such concentrations as used or found.

NIOSH received such a request from the Lumber and Sawmill Workers L.P.I.W. Loca 1 Union 3038, Missoula, Montana, to evaluate potential exposure to plywood veneer dryer emissions at the Champion Building Products, Bonner, Montana.

IV. HEALTH HAZARD EVALUATION

\section{A. Plant Process}

Champion Building Products manufactures plywood. The veneer is peeled in an adjacent area of the plant. The veneer sheets are hand-fed into five continuous-feed, steam-heated veneer dryers which dry the veneer to a predetermined moisture content. As the dried veneer sheets exit 
Health Hazard Evaluation

Report No. 78-21, Page 3

from the dryer, they are removed by hand and graded. The veneer sheets are subsequently joined, patched, and assembled into panels which are then glued, pressed, trimmed, sanded, and graded. This request involves only the veneer drying areas.

This company has five steam-heated veneer dryers in operation at the present time. Veneer dryers are usually equipped to carry the stock through the dryer by a series of rolls. The rolls comprise a line with the dryers usually containing from four to eight lines. The lines are enclosed in a shell of sheet metal which is divided into sections. The shell also contains fans, ducts, and baffles for circulating and directing heat to the various lines. The temperatures used are usually less than $400^{\circ} \mathrm{F}$. (Figure 1 is a schematic diagram of a typical dryer.)

As the water is given up by the heated veneer, it is converted to steam and when mixed with air makes an excellent drying medium. The amount of moisture in the dryer is controlled by dampers in the venting stacks which allow excess steam to escape into the atmosphere. The air-steam mixture is kept in constant circulation by the large fans in the dryer.

Since there are large fans circulating the air in the dryers, a portion of the air in the dryer is under negative pressure and a portion is under positive pressure. Air under positive pressure will seek out cracks and openings. Since a dryer has leaks around door seals, and also is open on both the feeding and grading end of the dryer, the air escapes from the dryer into the surrounding room atmosphere.

The air that escapes from the dryer will contain steam plus all the hydrocarbons that were colatilized from the wood. The hydrocarbons include alcohols, ketones, esters, aldehydes, terpenes, fatty acids and resin acids. The hydrocarbons can be divided into two categories--those that condense at ambient temperatures and those that remain volatile at ambient temperatures.

During this evaluation veneer was made from $5 \%$ pine, $80 \%$ fir, and $15 \%$ larch. The largest portion of the volatile hydrocarbons consist of $\alpha$ - and $\beta$-pinene; and the majority of the condensed hydrocarbons are abietic and pimaric acids.

B. Evaluation Design and Methods

1. Environmental Evaluation

This evaluation consisted of measuring the concentration of $\alpha-$ and $\beta-p i n e n e$ as turpentine and abietic and pimaric acids as total acids in the area of the plywood veneer dryer workers.

On February 5-9, 1978, samples were collected in the general work area of the plywood veneer feeders, graders and dryer tenders. "Area samples" rather than "personal samples" had to be collected because of the 110 volt $A C$ power requirement for the electrostatic precipitator units. It was felt that these "area samples" would be representative of employee exposure to veneer dryer emissions since the persons involved in the dryer operations generally work 25 to 40 feet from the dryer, and spend greater than $90 \%$ of their time in the immediate area of the dryer. 
Health Hazard Evaluation

Report No. 78-21, Page 4

a. Total Acids - General area. acid samples were collected using three Bendix Electrostatic Precipitator units at 12,000 volts $D C$ and at a flow rate of from $4.65 \mathrm{cfm}$ to $8.55 \mathrm{cfm}$. (Each unit had a different flow rate. See Figure 2 for a diagram of the sampling train.) The ESP tubes were forwarded to the Utah Biomedical Test Laboratory (UBTL) for total acid determination.

b. $\alpha$ - and $\beta$-pinenes - General area samples were collected on charcoal tubes using MSA personal sampling pumps at a flow rate of 1.0 liters per minute. The samples were collected in the exhaust of the ESP units as the acids, if not removed, would interfere with the adsorption of the pinenes on the charcoal. (See Figure 2 for a diagram of the sampling train.) The charcoal tubes were analyzed by UBTL for turpentine.

\section{Medical Evaluation}

The initial survey, industrial hygiene survey, and medical survey were all conducted at a single unannounced visit. The surveys were conducted at the Champion Building Products, plywood production facility, on February 6-10, 1978. The decision to arrive at the Champion facility unannounced was made at the request of the local union. The opening conference was conducted by two NIOSH industrial hygienists. The medical personnel arrived later. The NIOSH medical personnel consisted of two physicians, a physician's assistant, and a medical technician. The medical survey began on February 8 and ended February 9, 1978. The union contacted its personnel working in the vicinity of the veneer drying ovens to notify them of the hazard evaluation and to instruct them on the time of evaluation of each shift. The company provided office space for conducting the evaluation in close proximity to the work station.

During the second day of this survey, the NIOSH medical personnel were given a tour of the production areas, eating area and first aid facilities. The production area is enclosed in a very large room with a high ceiling. The portion containing the veneer dryers was partially partitioned off by a screen hanging from the ceiling to approximately one-half the distance to the floor. This was to enclose the smoke created by the dryers. A cloud of smoke was apparent on the dryer side of the screen. On the opposite side, a haze of smoke still existed but was much less extensive than the dryer side. A turpentine odor was always noticeable. A separate lunch room with hand washing facilities was present. The first aid facilities were enclosed in the security station in a separate building. A registered nurse was reported to be present at all times except from 6:00 p.m. Saturdays until 11:00 p.m. Sundays. During these times, first aid trained supervisors and employees are reported to be present inside the plant. The first aid room was extremely clean and well maintained. It contained an examination table, bandages, and antiseptic solutions, as well as oxygen and intravenous solutions 
realth Hazard Evaluation

Report No. 78-21, Page 5

for more serious trauma. Transportation of such workers has been arranged through a local ambulance service. The nurses were also providing a blood pressure surveillance service for employees at the infirmary.

Medical services have been contracted through a local physician's clinic. The medical program consists of a pre-employment evaluation which includes a history evaluation, physical examination, urine analysis, audiogram, and back x-ray. Period evaluations consist of a audiogram and blood pressure check annually.

METHODS

The medical study consisted of a primary questionnaire, a mini-questionnaire, a limited physical evaluation, and pulmonary function tests.

The primary questionnaire was designed to elicit demographic information, work history, general past medical history, specific medical information concerning pulmonary disease or dysfunction, and smoking history. This questionnaire was given either during the pre- or post-shift evaluation. The medical history questions contained some specific and general questions. (Table 2)

The mini-questionnaire was a list of questions, both general and specific, directed toward anatomic or functional body units (eg. nasal complaints). They were given during both the pre- and post-period to determine an onset of complaints during the course of the shift. If a positive response was elicited, the physician then asked questions to determine the relevance of the response. The pre- shift period was defined as just prior to or within two hours of arriving at the workplace; and the post- shift period was defined as just after or within two hours of finishing work. There must have been at least four hours of work exposure between the pre-shift and post-shift evaluations for the worker to have been included in the evaluation.

Each worker was given two limited physical examinations by a NIOSH physician. The examinations consisted of inspection of the conjunctiva, nasal mucous membranes and the pharynx. Auscultation of the thorax was performed. The examinations were performed during the pre- and post-shift periods to determine any change over the course of the shift.

Pulmonary function tests were performed. The units used were Medistor* pulmonary function machines with a digital readout both on a screen and a printer. The electrical circuity of each unit was tested for calibration daily with the manufacturer's directions. The units were operated by the physician's assistant and the medical technician. Each study participant was given verbal instructions by the operator

* Mention of trade name does not constitute NIOSH endorsement. 
and was given several (at least two) practice attempts on the unit. The pulmonary function parameters studied were (1) forced vital capacity (FVC), (2) forced expiratory volume in the first second of exhalation $\left(F E V_{1}\right),(3)$ the ratio of $F E V$ /FVC to determine the percentage of the FVC expelled in the first second, and (4) the forced expiratory flow during the mid fifty percent of exhalation (FEF 25-75). The normal values for the FVC, FEV 7 , and FEF 25-75 were determined for each individual from the prediction nomograms of Morris, et al. I for FVC, FEV 1 , and FEF 25-75. In the notification letters to the workers a value of $75 \%$ or greater was used as normal for $\mathrm{FEV}_{1} / \mathrm{FVC}$.

The participants were divided into groups by sex and smoking history (smokers, ex-smokers, and non-smokers) for the evaluation of pulmonary function test results. The two sets of data, pre- and post- shift for each individual in the group, were analyzed as paired data using the paired t-test. The significant level for the statistical analysis was chosen at the 95th percentile $(p<.05)$. The raw pulmonary function values were used in this test, not the percent of predicted. The observed pre-shift values were compared with expected values for all groups also at the $p<.05$ level.

The association between the reported frequency of symptoms related to pulmonary function and smoking history (combining male and female) was explored using a $x^{2}$-test. The difference between frequency of reporting each symptom (within smoking categories) between sexes was also evaluated.

The variable exposure years was calculated for each individual by a number of years at a high risk job. The relationsip between this variable and pre-shift pulmonary function differences ( $F E V_{1}$, FVC and FEF 25-75) was assessed within sex and smoking categories using the calculated correlation coefficient.

\section{Evaluation Criteria}

\section{Environmental Standards}

Currently there are no Federal occupational health standards or any recommended levels for $\alpha$ - and $\beta$-pinene, abietic or pimaric acids. The range and mean for levels found in plywood veneer plants are presented below:

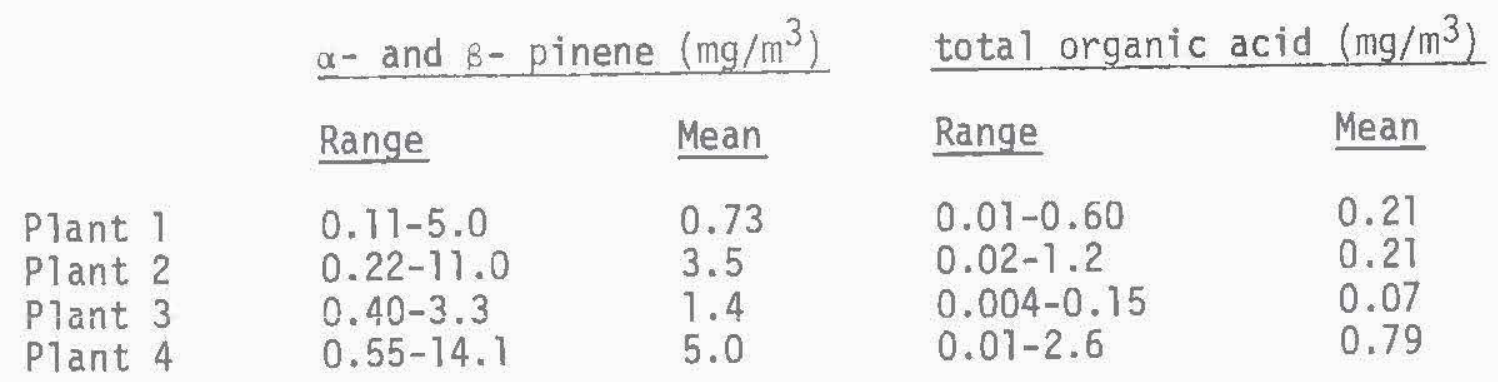


Health Hazard Evaluation

Report No. 78-21, Page 7

\section{Medical Standards}

The medical criteria used to determine a toxic response to veneer dryer emissions under investigation consist of the signs and symptoms associated w1th exposure to the major substances found in the veneer dryer emissions. The veneer dryer emissions consist basically of warm air, water vapor, a small amount of particulate matter, and hydrocarbons. The hydrocarbons consist of two components-those that condense readily on contact with the amblent air and those that remain volatile. Those that remain volatile are principally $\alpha$ - and $B$-pinene. Those that are condensed are principally abietic and pimaric acids.2,3 The 11 terature on these substances is scanty but a review of the current literature plus information on previously studied plywood veneer plants is given below:

a. Pinenes: The pinenes are colorless to yellow liquids with the odor of turpentine. They are the major constituents of oil of turpentine. Pinenes have the following physical properties: mol. wt., 136.2; melting point $55^{\circ} \mathrm{C}$; flashpoint, $91^{\circ} \mathrm{F}$; density, 0.8585 at the $20^{\circ} \mathrm{C}$; vapor pressure, $10 \mathrm{~mm}$ at $37.3^{\circ} \mathrm{C}$; vapor density, 4.7. The following information has been obtained from the Hygienic Guide Series on Turpentine.

The toxic properties of the pinenes include:

(1) Inhalation: Among the effects observed in humans subjected to severe exposure were irritation of mucous membranes of nose and throat, cough, bronchial inflammation, salivation, headache, vertigo, and irritation of the kidneys and bladder. It has been reported that continued inhalation of the vapor may cause chronic nephritis and predispose to pneumonia. Albuminuria and hamaturia have been reported in men exposed to turpentine vapor w1 th subsequent recovery from such exposures. ${ }^{4}$ There is little evidence to suggest that turpentine vapors at low levels are a chronic poison. There is scanty evidence to suggest that some individuals may develop a hypersensitivity to turpentine after prolonged, repeated exposures.

(2) Skin Contact: There is little doubt that turpentine is a skin irritant for normal persons if allowed to remain in contact with skin for a sufficient length of time. Some persons are so sensitive that even moderate exposure to vapors will cause a skin reaction. Most people do not develop a dermatitis from occasional contact. $2,3,5$

(3) Eye Contact: A vapor concentration of $200 \mathrm{ppm}$ is moderately irritating to the eyes.

b. Abietic Acid: Abietic acid is a yellow powder with the following physical properties: mol. wt., 302-44, melting point, $137-166^{\circ} \mathrm{C}$. There are scanty toxicological data avallable on this chemical. According to Patty, abietic acid has a low oral toxicity 
Health Hazard Evaluation

Report No. 78-21, Page 8

and is not a skin irritant. However, other sources claim that abletic acid is slightly toxic and slightly irritating to the skin and mucous membranes.5

c. Pimaric Acid: No information is avallable on this agent either in the standard references or in the current NIOSH Toxic Substance List.

A1l four studies determined that under normal working conditions veneer dryer enissions may produce transient irritation of the mucous membranes of the eyes, nose and throat, as well as the upper respiratory tract, producing cough and chest discomfort to workers in dryer operations. The emissions, which are principally abletic and pimaric acids (condensed hydrocarbons) and $a-$ and $\beta$-pinene (volatile hydrocarbons), are most pronounced when Douglas and White Fir are being dried. Veneer dryer emissions as well as smoke from fires that occasionally break out in the dryers, may translently aggravate any underlying asthmatic or other chronic respiratory condition and may make hay fever symptomatically worse.

Pulmonary function tests in two of the four plants studied revealed small decrements in forced expiratory flow and maximal midexpiration flow rates over the course of the usual work shift, but these findings were too inconsistent to make any firm conclusions. Periodic (annual) pulmonary function testing of exposed workers along with a control (unexposed) group would evaluate this matter completely. There is no evidence from the present surveys to suggest that veneer dryer emissions cause allergic pulmonary disease or hay fever.

D. Evaluation Results

1. Environmental Results

Twenty-three area samples for total acids and 21 area samples for pinenes were collected. The samples were collected on all shifts on February 5-9, 1978. The individual sample results for the total acids and pinenes measured as turpentine are listed in Tables 6 and 7 . The total acid concentrations ranged from none detected to over $2.5 \mathrm{mg} / \mathrm{M}^{3}$. The pinene concentrations (measured as turpentine) ranged from 0.55 to $14.13 \mathrm{mg} / \mathrm{M}^{3}$.

Over $90 \%$ of the employee's time was spent in the general area of the plywood veneer dryers. Therefore, the area samples were considered to be representative of employee exposure to plywood veneer dryer emissions over the course of the work shift.

\section{Medical Results}

The demographic data describing the participating workers are presented in Table 1. Sixty-seven (67) workers expressed interest in the study, but only fifty-eight (58) could participate in the entire evaluation. The remaining nine (9) persons were not included in all 
Health Hazard Evaluation

Report No. 78-21, Page 9

statistical evaluations because they either did not return for the postshift evaluation, or they did not complete the history questionnaire.

If they did, however, participate in any portion of the hazard evaluation sufficiently to have useable data, that data was used in the statistical evaluation.

The results of the primary questionnaire are presented in Table 3 . The percentage of positive responses for each group is listed.

The mini-questionnaire data are presented in Table 4 . The percentage of persons in each group who developed a symptom relevant to a particular anatomic of functional body unit during the course of the shift are listed. It was noted that there were persons who had pre-shift complaints who did not report these symptoms in the post-shift questionnaire.

The most frequent complaints upon review of Tables 3 and 4 were those pertaining to the upper respiratory tract, lower respiratory tract, and conjunctiva.

When comparing these responses in relationship to smoking history, only symptom $C$, "tearing of the eyes", was related to smoking. When comparing across smoking groups, males reported symptom $A$, "dry or sore throat", more often than females.

Nasal, eye and chest symptoms were the most frequent during-the-shift complaints.

Pre- and post- shift physical examinations were performed on 61 of the workers. Twelve (12) workers developed a slight redness of the conjunctiva. Two (2) workers developed slight wheezing during the course of the shift.

The pulmonary function tests constituted the major portion of the hazard evaluation. There were no significant differences between the pre- and post- shift pulmonary function parameters, FVC, FEV 1 , FEF 25-75, with sex and smoking history. High-risk jobs are those at or very near the veneer drying ovens. Exposure to the emissions is considered greater at these locations. A paired t-test showed a statistical difference between the best observed pre-shift value and the expected for male and female smokers for a11 pulmonary function varibles. This difference was not seen for ex-smokers or non-smokers. Individual pulmonary function values are presented in Table 5 for the fifty-eight workers providing sufficient information for analysis.

V. SUMMARY AND CONCLUSIONS

The questionnaire data indicate that a large number of workers complain of upper respiratory irritation, dry throats, stuffy nose, running nose, coughing, burning or itching eyes, or chest tightness or wheezing. No objective findings, however, can be documented in the working population via pulmonary function tests. Since no statistical difference was seen between the observed and predicted for non- and ex-smokers we cannot believe that the reducted observed values for smokers was related to veneer emission exposure. No relationship between pulmonary function can be seen over the course of the shift or correlated with years

exposure to veneer drying emissions. There was, however, mild conjunctiva irritation during the course of the shift. 
Health Hazard Evaluation

Report No. 78-21, Page 10

\section{RECOMMENDATIONS}

1. Door seals on veneer dryers should be cleaned and repaired to prevent leakage.

2. Shroud should be over both feeder and offbear (grader) ends. Feeders should be positioned outside shroud. Feeders 2 and 3 are outside shroud and it is easy to see a decrease in haze at these feeder locations.

3. Roof ventilators should consist of exhaust fans inside the shrouded areas. The exhaust discharges should be through a vertical discharge stack high enough to prevent re-entry of dryer emissions. Shrouded area should have a negatlve pressure to surroundings.

4. Makeup afr between dryers may have to be added to assist in removal of emissions between dryers.

5. Emissions exhausted by these systems should not be permitted to re-enter the same or other work areas.

6. The veneer dryers should be cleaned at intervais frequent enough to prevent fires from developing in the dryers.

7. The dryer tender is an important worker in controlling the dryer emisstons. An increased emphasis in this job should aid in keeping the dryer emissions into the work areas to a minimum.

8. Medical monttoring and education is recommended for all workers assigned to dryer operations:

a. These workers should be made aware of the irritant effects produced by veneer dryer emissions.

b. Pre-assignment histories and physical examinations should be carried out on all employees, and perfodically repeated.

c. Pre-assignment and subsequent periodic (annual) pulmonary function testing (to include FVC, FEV 1.0 , and MMEF 25-75\%) should be considered for emplovees in veneer dryer operations.

d. Individuals with a history of asthma or other chronic respiratory condition which is reported or detected by pulmonary function testing should be advised that their condition may be made symptomatically worse by working in close proximity to the veneer dryers. 
Health Hazard Evaluation

Report No. 78-21, Page 11

\section{REFERENCES}

1. Morris, J.F., Arthur Kosk1, and Lavon C. Johnson: Spirometric Standards for Healthy Non-smoking Adults. American Review of

Respiratory Disease, p. 103:57-67 (1971).

2. Patty, F.A. ed: Industrial Hygiene and Toxicology, Vol. II, 2nd ed., p. 1214, Interscience Publishers, New York (1963).

3. Schwartz, L., L. Tulipau, and S.M. Peck: Occupational

Disease of the Skin, 2nd ed.. Pp. 534-4, Lea and Febiger,

Philadelphia, Pa., (1947).

4. Chapman, E.M.: Observations on the Effects of Paint on the Kidneys with Particular Reference to the Role of Turpentine.

J. Ind. Hyg. Toxicology, 23:277 (1941).

5. Jacobs, M.D.: The Analytical Chemistry of Industrial Poisons, Hazaras and Solvents. 2nd Ed., pp. 553-554. Interscience Publishers, New York (1949).

6. R. Rostand and A. Apol; Health Hazard Evaluation Determination Report \#72-121-242, DHEW, CDC, NIDSH - December, 1975.

7. R. Rostand and A. Apol; Heaith Hazard Evaluation Determination Report \#73-57-243; DHEW, CDC, NIOSH - December, 1975.

8. B. Gunter, R. Rostand, R. Nickeson; Health Hazard Evaluation Determination Report \#73-110-278; DHEW, CDC, NIOSH - Apri1, 1976.

VIII. AUTHORSHIP AND ACKNOWLEDGMENTS

Report Prepared By:

\author{
Bobby J. Gunter, Ph.D. \\ Regional Industrial Hygienist \\ NIOSH - Region VIII \\ Denver, Colorado \\ Arvin G. Apol \\ Regional Industrial Hygienist \\ NIOSH - Region X \\ Seattle, Washington \\ Jeffrey Lybarger, M.D. \\ Medical Section \\ Hazard Evaluations and Technical \\ Assistance Branch \\ NIOSH - Cincinnati, Ohio
}


Health Hazard Evaluation

Report No. 78-21, Page 12

Medical Examinations:

Pulmonary Function:

Statistical Support:

Originating office:

Report Typed By:
Charles Wisseman, M.D.

Medical Section

Hazard Evaluations and Technical

Assistance Branch

NIOSH - Cincinnati, Ohio

Robert Schutte

Support Services Branch, DSHEFS

NIOSH - Cincinnati, Ohto

Raymond Stroman, $M x$

Medical Section

Hazard Evaluation and Technical

Assistance. Branch

Cincinnati, Ohio

JeAnne Burg, Ph.D.

Support Services Branch, DSHEFS

NiOSH - Cincinnati, Ohio

SWORC

NIOSH - Cincinnati, Ohio

Jerome P. Flesch, Chief

Hazard Evaluations and Technical

Assistance Branch

NIOSH - Cincinnati, Ohio

Marilyn K. Schulenberg

NIOSH - Region VIII

Denver, Colorado

Patricia Dove

Medical Section

Hazard Evaluation and Technical

Assistance Branc

NIOSH - Cincinnati, Ohio 


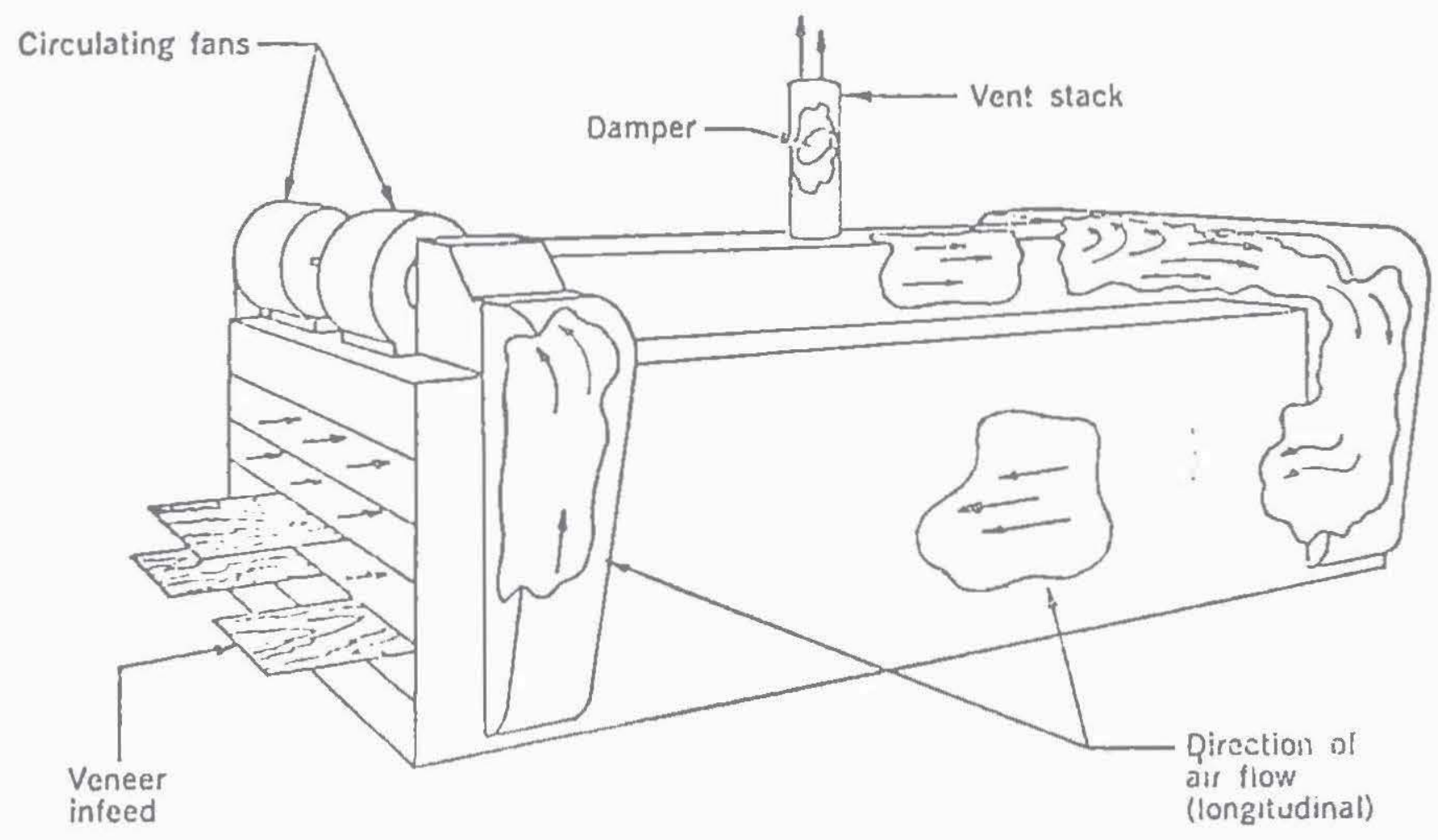

Figure 1/Veneer Diyer (Silligle Zone) 


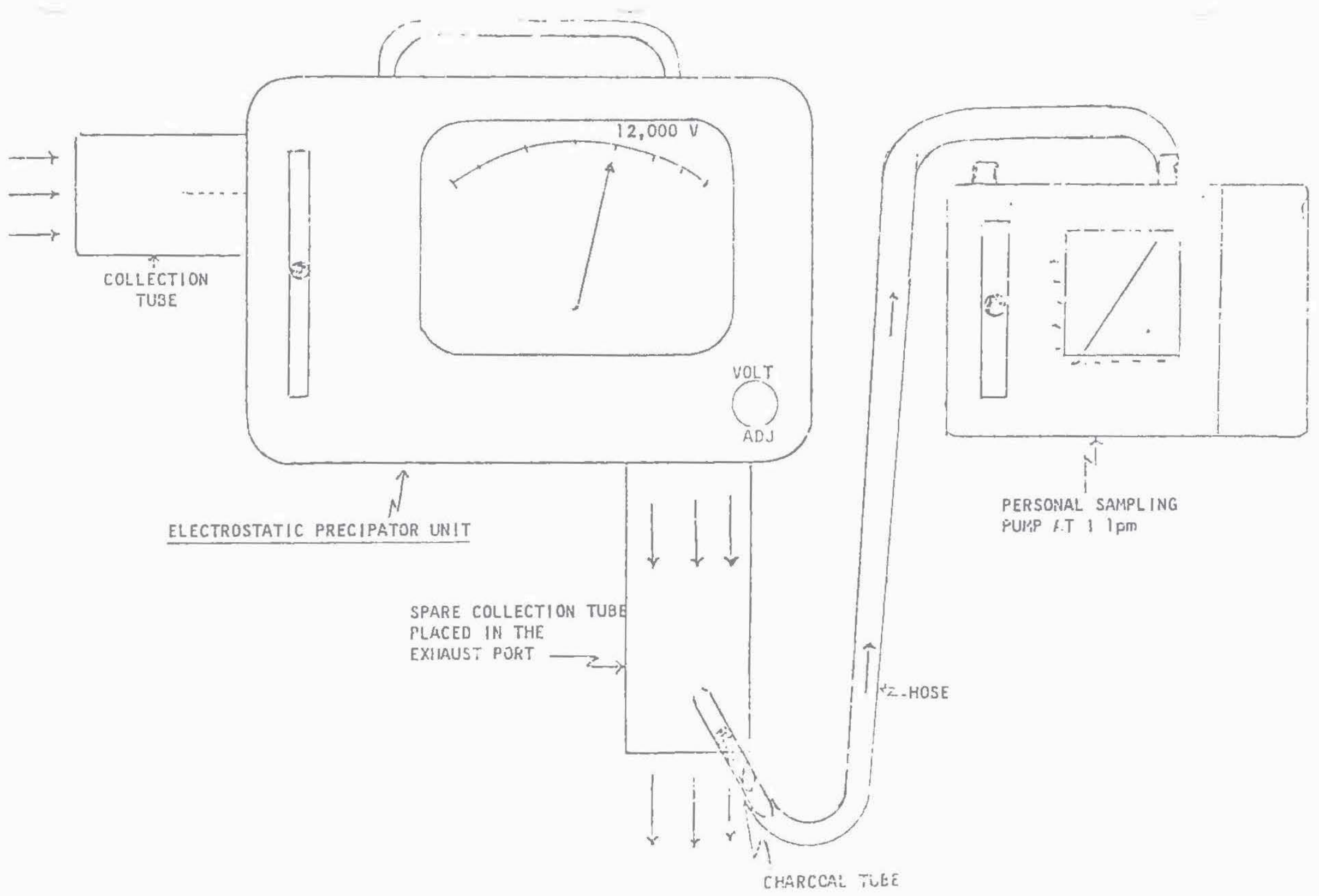

FIGURE 2. SAMPLING SCHEMATIC DIAGRAM 


\section{Table 1}

Champion Building Products Co. HHE 78-21

February 8-9, 1978

Demography

(of all 67 participants in some aspect of the health evaluation.)

Gender

Males

Females

Smoking History

Smokers

Ex-smokers

Non-smokers

Age

All participants providing information
A11 registrants Pulmonary $f x$ in study

36

31

32

26

25

22

19

16

23

20

Mean

S.D.

32.06

8.41 
Table 2

Champion Bullding Product Co. HHE 78-21

February 8-9, 1978

Questionnaire Information Elicited Concerning Medical History

Medical Symptoms

A. Dry or sore throat

B. Burning or itching eyes

C. Tearing of the eyes

D. Stuffy nose

E. Runny nose

F. Coughing

G. Chest tightness, soreness, or heaviness

H. Wheezing or whistling in your chest

I. Shortness of breath

J. Burning on urination

K. Nausea and/or vomiting

L. Weight loss

M. Muscle weakness

N. Loss of consciousness

Past Medical Illnesses

a. Chest or lung problems

b. Heart problems

c. Pneumonia

d. Pulmonary TB

e. Bronchial asthma

f. Skin rash or other skin problems

g. Gastrointestinal problems

h. Kidney or bladder problems

i. Neurological problems 
TabTe 3

Champion Building Products Co.

HHE 78-21

February 8-9, 1978

Percent of each group responding positively to the question in Table 2

\begin{tabular}{|c|c|c|c|c|c|c|c|c|c|c|c|c|}
\hline \multirow{2}{*}{$\begin{array}{c}\text { Question } \\
\text { (From Table 2) }\end{array}$} & \multirow[b]{2}{*}{$\begin{array}{c}\text { Ex-Smokers } \\
\%\end{array}$} & \multirow[b]{2}{*}{$\begin{array}{c}\text { Smokers } \\
\%\end{array}$} & \multirow[b]{2}{*}{$\underset{\%}{\text { Non-Smokers }}$} & \multirow[b]{2}{*}{$\begin{array}{c}\text { Male } \\
\%\end{array}$} & \multirow[b]{2}{*}{$\underset{\%}{\text { Female }}$} & \multicolumn{2}{|c|}{ Smokers } & \multicolumn{2}{|c|}{ Ex-Smokers } & \multicolumn{2}{|c|}{ Non-Smokers } & \multirow[t]{2}{*}{ Tota 1} \\
\hline & & & & & & Male & Fema le & Male & Female & Male & Fema le & \\
\hline A & 68 & 60 & 52 & 69 & 50 & 80 & 47 & 64 & 80 & 64 & 42 & 60 \\
\hline $\begin{array}{l}A \\
B\end{array}$ & 68 & 72 & 67 & 71 & 63 & 100 & 53 & 64 & 80 & 55 & 67 & 67 \\
\hline C & 37 & 64 & 35 & 54 & 38 & 90 & 47 & 36 & 40 & 45 & 25 & 46 \\
\hline D & 63 & 56 & 70 & 71 & 53 & 70 & 47 & 64 & 60 & 86 & 58 & 63 \\
\hline E & 53 & 44 & 35 & 54 & 31 & 60 & 38 & 57 & 40 & 45 & 25 & 43 \\
\hline$F$ & 37 & 48 & 39 & 37 & 47 & 50 & 47 & 36 & 40 & 27 & 50 & 42 \\
\hline G & 37 & 28 & 26 & 37 & 22 & 40 & 20 & 36 & 40 & 36 & 17 & 30 \\
\hline H & 16 & 24 & 4 & 17 & 13 & 30 & 20 & 14 & 40 & 9 & 0 & 15 \\
\hline I & 26 & 32 & 26 & 26 & 31 & 40 & 27 & 14 & 60 & 27 & 25 & 28 \\
\hline $\mathrm{j}$ & 5 & 8 & 0 & 6 & 3 & 10 & 7 & 7 & 0 & 0 & 0 & 5 \\
\hline K & 0 & 24 & 13 & 11 & 19 & 30 & 20 & 7 & 0 & 0 & 25 & 15 \\
\hline$\ddot{L}$ & 5 & 16 & 0 & 6 & 6 & 20 & 14 & 0 & 0 & 0 & 0 & 6 \\
\hline$M$ & 5 & 12 & 4 & 6 & 9 & 10 & 14 & 0 & 10 & 9 & 0 & 7 \\
\hline N & 0 & 8 & 0 & 3 & 3 & 10 & 7 & 0 & 0 & 0 & 0 & 3 \\
\hline a & 11 & 8 & 4 & 9 & 6 & 0 & 14 & 14 & 0 & 9 & 0 & 7 \\
\hline $\mathrm{b}$ & 0 & 16 & 13 & 14 & 6 & 30 & 7 & 0 & 0 & 18 & 8 & 10 \\
\hline c & 11 & 24 & 0 & 14 & 9 & 30 & 20 & 14 & 0 & 0 & 0 & 12 \\
\hline d & 0 & 4 & 0 & 0 & 3 & 0 & 7 & 0 & 0 & 0 & 0 & 1 \\
\hline e & 5 & 0 & 4 & 6 & 0 & 0 & 0 & 7 & 36 & 10 & 0 & 3 \\
\hline$f$ & 32 & 24 & 4 & 28 & 28 & 30 & 20 & 36 & 10 & 9 & 42 & 27 \\
\hline g & 27 & 24 & 22 & 9 & 23 & 10 & 33 & 14 & 20 & 0 & 0 & 15 \\
\hline h & 5 & 4 & 0 & 3 & 3 & 0 & 7 & 7 & 0 & 0 & 0 & 3 \\
\hline i & 5 & 4 & 4 & 3 & 6 & 0 & 7 & 7 & 0 & 0 & 8 & 4 \\
\hline
\end{tabular}




\section{Table 4}

Champion Building Products Co.

HHE 78-21

February 8-9, 1978

Percent Developing Symptoms During Work

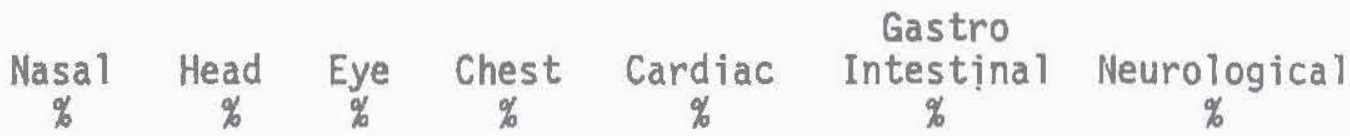

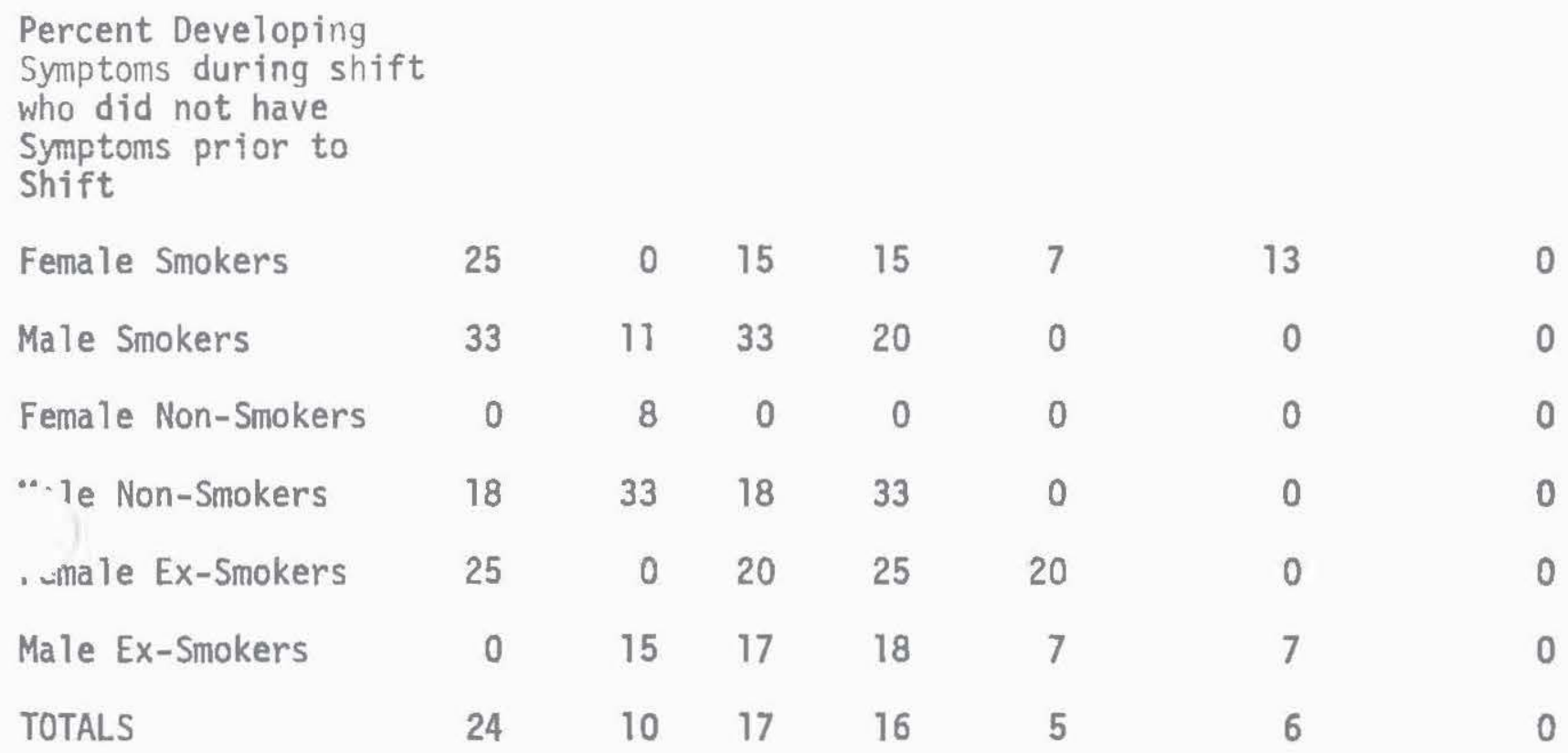


Table 5

Champion Building Products Co.
HHE $78-21$

February 8-9, 1978

Pulmonary Function Data

\begin{tabular}{|c|c|c|c|c|c|c|c|c|}
\hline \multirow[b]{2}{*}{ \# } & \multirow[b]{2}{*}{ Sex } & \multirow[b]{2}{*}{ Smoking } & \multicolumn{3}{|c|}{ Pre-Shif } & \multicolumn{3}{|c|}{ Post-Shift } \\
\hline & & & $\begin{array}{l}\text { FVC } \\
\text { liters }\end{array}$ & $\underset{\mathrm{FEV}}{\mathrm{Fters} / \mathrm{sec}}$ & $\begin{array}{r}\text { FEF } 25-75 \\
\text { 1iters } / \mathrm{sec}\end{array}$ & $\begin{array}{c}\text { FVC } \\
\text { liters }\end{array}$ & $\begin{array}{l}\mathrm{FEV} \\
\text { liters }\end{array}$ & $\begin{array}{l}\text { FEF } 25-7 \\
\text { Titers/se }\end{array}$ \\
\hline 1 & $\mathrm{~F}$ & N & 3.12 & 2.76 & 3.90 & 3.14 & 2.64 & 3.49 \\
\hline 2 & $\mathrm{~F}$ & N & 2.19 & 1.99 & 5.60 & 2.68 & 2.08 & 2.43 \\
\hline 3 & $\mathrm{~F}$ & s & 2.75 & 2.27 & 3.18 & 2.66 & 2.25 & 2.49 \\
\hline 4 & M & N & 5.19 & 4.50 & 5.80 & 4.88 & 4.35 & 6.23 \\
\hline 5 & M & s & 4.80 & 3.73 & 3.46 & 4.77 & 3.56 & 3.28 \\
\hline 6 & M & E & 4.13 & 2.84 & 2.10 & 4.19 & 2.82 & 1.84 \\
\hline 7 & $\mathrm{~F}$ & $\bar{N}$ & 3.77 & 3.17 & 3.34 & 3.76 & 3.27 & 4.18 \\
\hline 8 & i & E & 4.99 & 4.30 & 4.69 & 4.59 & 3.97 & 5.09 \\
\hline 0 & M & $\bar{N}$ & 5.23 & 4.25 & 4.57 & 5.32 & 4.07 & 4.61 \\
\hline 10 & M & E & 3.92 & 3.26 & 4.70 & 4.01 & 3.26 & 4.13 \\
\hline 11 & $\mathrm{~F}$ & s & 2.87 & 1.64 & .56 & 3.06 & 1.83 & .74 \\
\hline 12 & M & $E$ & 5.63 & 3.43 & 2.94 & 5.93 & 1.91 & 2.07 \\
\hline 13 & M & S & 2.27 & 1.74 & 1.36 & 3.96 & 2.96 & 2.37 \\
\hline 14 & $\mathrm{~F}$ & s & 3.09 & 2.22 & 2.43 & 2.78 & 2.04 & 2.66 \\
\hline 15 & $\mathrm{~F}$ & $S$ & 3.81 & 2.25 & 1.85 & 3.85 & 2.55 & 2.10 \\
\hline 16 & M & S & 3.61 & 2.78 & 2.45 & 3.84 & 3.14 & 3.73 \\
\hline 17 & $\mathrm{~F}$ & $s$ & 3.17 & 2.37 & 2.00 & 3.56 & 2.41 & 1.48 \\
\hline 18 & $\mathrm{~F}$ & N & 3.46 & 3.08 & 3.95 & 3.38 & 3.03 & 4.23 \\
\hline 19 & M & $\mathrm{s}$ & 5.05 & 4.23 & 4.94 & 4.92 & 3.80 & 3.48 \\
\hline 20 & $M$ & $E$ & 5.74 & 4.49 & 4.49 & 5.51 & 4.43 & 5.49 \\
\hline 21 & M & $E$ & 4.80 & 3.72 & 3.63 & 4.74 & 3.64 & 3.49 \\
\hline 22 & M & S & 4.21 & 3.42 & 3.73 & 4.11 & 3.28 & 3.60 \\
\hline 23 & $\mathrm{~F}$ & N & 4.34 & 3.37 & 3.47 & 4.72 & 3.15 & 2.28 \\
\hline 24 & $\mathrm{~F}$ & N & 3.04 & 1.84 & 2.62 & 3.18 & 2.69 & 4.90 \\
\hline 25 & M & $S$ & 4.65 & 3.49 & 3.54 & 4.56 & 3.36 & 2.84 \\
\hline 26 & M & $S$ & 5.25 & 4.09 & 3.92 & 5.72 & 4.25 & 3.99 \\
\hline 27 & M & N & 3.99 & 3.11 & 2.98 & 3.12 & 2.42 & 2.20 \\
\hline 28 & $\mathrm{~F}$ & $E$ & 2.54 & 2.09 & 2.18 & 2.42 & 2.01 & 2.54 \\
\hline 29 & M & $E$ & 5.12 & 3.32 & 2.91 & 5.15 & 2.81 & 2.11 \\
\hline 30 & M & E & 5.39 & 2.43 & 2.59 & 5.36 & 3.65 & 2.53 \\
\hline 31 & $F$ & E & 4.06 & 3.52 & 4.23 & 3.82 & 3.41 & 4.45 \\
\hline 32 & M & E & 4.51 & 3.06 & 2.26 & 4.09 & 2.84 & 2.10 \\
\hline 33 & $F$ & $\mathrm{~N}$ & 3.02 & 2.69 & 3.25 & 2.84 & 2.63 & 3.54 \\
\hline 34 & $F$ & $\mathrm{~N}$ & 3.27 & 2.98 & 4.35 & 3.08 & 2.87 & 4.01 \\
\hline 35 & F & $\mathrm{s}$ & 2.84 & 2.13 & 2.10 & 2.63 & 1.92 & 1.91 \\
\hline
\end{tabular}




\begin{tabular}{|c|c|c|c|c|c|c|c|c|}
\hline \multirow[b]{2}{*}{ \# } & \multirow[b]{2}{*}{ Sex } & \multirow[b]{2}{*}{ Snoking } & \multicolumn{3}{|c|}{ Pre-Shift } & \multicolumn{3}{|c|}{ Post-Shift } \\
\hline & & & $\begin{array}{l}\text { FVC } \\
\text { 1tters }\end{array}$ & $\begin{array}{c}\mathrm{FEV} \\
\text { liters/sec }\end{array}$ & $\begin{array}{l}\text { FEF } 25-75 \\
1 \text { iters/sec }\end{array}$ & $\begin{array}{c}\text { FVC } \\
\text { liters }\end{array}$ & $\begin{array}{l}\text { FEV } \\
\text { liters }\end{array}$ & $\begin{array}{r}\text { FEF } 25 \\
\text { liters/ }\end{array}$ \\
\hline 36 & M & S & 5.67 & 4.02 & 3.91 & 5.32 & 4.02 & 3.90 \\
\hline 37 & M & N & 5.87 & 4.03 & 3.92 & 5.69 & 4.43 & 3.82 \\
\hline 38 & $\mathrm{~F}$ & $\mathrm{~S}$ & 3.65 & 3.10 & 3.78 & 3.73 & 2.31 & 2.77 \\
\hline 39 & M & 5 & 3.86 & 3.19 & 4.05 & 3.80 & 3.04 & 4.39 \\
\hline 40 & $M$ & E & 4.60 & 3.99 & 5.62 & 4.51 & 3.81 & 4.17 \\
\hline 41 & M & $\bar{E}$ & 5.58 & 4.47 & 5.19 & 5.57 & 4.40 & 4.78 \\
\hline 42 & M & S & 4.69 & 3.55 & 4.76 & 4.81 & 3.18 & 3.71 \\
\hline 43 & $\mathrm{~F}$ & $\mathrm{~S}$ & 2.71 & 1.96 & 1.45 & 2.82 & 1.96 & 1.20 \\
\hline 44 & $\mathrm{~F}$ & $\mathrm{~S}$ & 4.07 & 3.03 & 2.46 & 3.91 & 2.85 & 2.49 \\
\hline 45 & $M$ & N & 4.65 & 2.69 & 2.25 & 4.66 & 2.85 & 2.36 \\
\hline 46 & $\mathrm{~F}$ & s & 3.31 & 2.45 & 2.07 & 3.23 & 2.33 & 2.07 \\
\hline 47 & M & $E$ & 5.66 & 3.43 & 2.07 & 5.51 & 3.25 & 2.05 \\
\hline 48 & $\mathrm{~F}$ & $\mathrm{~N}$ & 3.46 & 3.08 & 4.33 & 3.28 & 2.87 & 3.72 \\
\hline 49 & $\mathrm{~F}$ & S & 3.45 & 2.59 & 2.29 & 3.54 & 2.69 & 2.35 \\
\hline 50 & $F$ & $\mathbf{N}$ & 4.10 & 3.61 & 5.08 & 4.12 & 3.74 & 5.00 \\
\hline 51 & M & $\ddot{N}$ & 4.78 & 3.57 & 4.01 & 4.83 & 3.74 & 4.36 \\
\hline 52 & M & E & 6.17 & 2.01 & 2.83 & 5.85 & 2.91 & 2.22 \\
\hline 53 & F & $\mathrm{N}$ & 4.04 & 1.73 & ]. 64 & 3.98 & 1.25 & 1.34 \\
\hline 54 & M & $\mathrm{N}$ & 3.92 & 3.20 & 3.92 & 3.86 & 3.07 & 3.93 \\
\hline 55 & $F$ & E & 4.30 & 3.76 & 5.08 & 4.28 & 3.56 & 4.13 \\
\hline 56 & M & $\mathrm{N}$ & 5.79 & 4.49 & 4.12 & 6.22 & 4.48 & 3.55 \\
\hline 57 & $\mathrm{~F}$ & S & 3.30 & 2.38 & 2.21 & 3.33 & 2.49 & 2.44 \\
\hline 58 & $M$ & $N$ & 3.79 & 2.74 & 2.10 & 3.52 & 2.57 & 2.10 \\
\hline
\end{tabular}


Atmospheric Concentrations of

Pinene

Champion Building Products

February 6-7, 1978

Sample Number

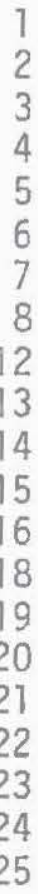

Location

\#5 Dryer/Lower Part

\#3 Dryer/Feeder End

\#2 Dryer/Off Bear

\#2 Dryer/Off Bear

\#5 Dryer/Lower Feeder

\#2 Dryer/Off Bear

\#5 Dryer/Top Feeder End

\#1 Dryer/Feeder End

\#5 Dryer/Lower Feeder End

\#4 Dryer/Feeder End

\#5 Dryer/Grader

\#5 Dryer/Feeder End

\#3 Dryer/Feeder End \#5 Dryer/Grader End Between \#4 and \#5 Dryers \#4 Dryer/Feeder End Between \#2 and \#3 Dryers \#2 Dryer/Feeder End Between \#3 and \#4 Dryers \#2 Dryer/Grader End \#2 Dryer/Feeder End
Time of Sample

$$
\begin{aligned}
& 3: 15 \text { PM - 7:10 PM } \\
& 3: 20 \mathrm{PM}-7: 10 \mathrm{PM} \\
& \text { 5:40 PM - 10:40 PM } \\
& \text { 5:40 PM - 10:40 PM } \\
& 10: 45 \text { AM - 3:45 PM } \\
& \text { 3:50 PM - 10:55 PM } \\
& \text { 10:45 PM - 7:00 AM } \\
& 10: 55 \text { PM - 6:50 AM } \\
& \text { 7:00 AM - 10:55 AM } \\
& 10: 30 \text { AM - 2:50 PM } \\
& 10: 45 \text { AM - 2:40 PM } \\
& 10: 55 \text { AM - 3:00 PM } \\
& 2: 40 \text { PM - 10:40 PM } \\
& \text { 3:00 PM - 11:00 PM } \\
& \text { 6:00 PM - 10:45 PM } \\
& 10: 45 \text { PM - 6:35 AM } \\
& 11: 05 \text { PM - 6:50 AM } \\
& 11: 00 P M-6: 50 \text { AM } \\
& 6: 50 \text { AM - 9:30 AM } \\
& 6: 45 \text { AM - 9:30 AM } \\
& \text { 6:50 AM - 9:30 AM }
\end{aligned}
$$

EVALUATION CRITERIA

\section{LABORATORY LIMIT OF DETECTION}

$\mathrm{mg} / \mathrm{M}^{3}=$ milligrams per cubic meter

* = there is no available standard or recommended level of safe exposure to total pinene
Pinene $\left(\mathrm{mg} / \mathrm{M}^{3}\right)$

$$
\begin{array}{r}
5.7 \\
5.5 \\
1.2 \\
9.73 \\
4.9 \\
0.68 \\
7.39 \\
4.61 \\
3.96 \\
6.81 \\
0.55 \\
3.55 \\
1.38 \\
6.08 \\
11.70 \\
0.98 \\
8.95 \\
12.19 \\
1.75 \\
1.52 \\
14.13
\end{array}
$$

0.01

$\mathrm{mg} / \mathrm{sample}$ 
Atmospheric Concentrations of Abietic and Pimaric Acids

Champion Building Products

February 6-7, $197 c$

Sample Number

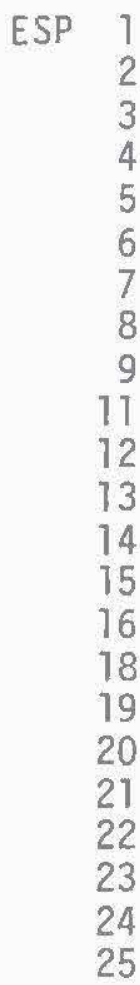

\section{Location}

\#5 Dryer/Lower Part \#3 Dryer/Feeder End \#2 Dryer/Off Bear \#2 Dryer/0ff Bear \#5 Dryer/Lower Feeder \#2 Dryer/0ff Bear *5 Dryer/Top Feeder End \#] Dryer/Feeder End \#4 Dryer/0ff Bear \#5 Dryer/Off Bear \#5 Dryer/Lower Feeder End \#4 Dryer/Feeder End \#5 Dryer/Grader \#5 Dryer/Feeder End \#3 Dryer/Feeder End \#5 Dryer/Grader End Between \#4 and \#5 Dryers \#4 Dryer/Feeder End Between \#2 and \#3 Dryers \#2 Dryer/Feeder End

Between \#3 and \#4 Dryers \#2 Dryer/Grader End \#2 Dryer/Feeder End

\section{Time of Sample}

3:15 PM - 7:10 PM $3: 20 \mathrm{PM}-7: 10 \mathrm{PM}$ 5:40 PM - 10:40 PM $5: 40 P M-10: 40 P M$ $10: 45$ AM - 3:45 PM $3: 50$ PM - 10:55 PM 10:45 PM - 7:00 AM $10: 55 P M-6: 50 A M$ 11:00 PM - 6:40 AM $6: 40$ AM - 10:45 AM 7:00 AM - 10:55 AM $10: 30$ AM - 2:50 PM $10: 45$ AM - 2:40 PM $10: 55$ AM - 3:00 PM $2: 40 \mathrm{PM}-10: 40 \mathrm{PM}$ 3:00 PM - 11:00 PM $6: 00$ PM - 10:45 PM $10: 45 P M-6: 35$ AM

$11: 05$ PM - 6:50 AM

$11: 00 \mathrm{PM}$ - 6:50 AM

$6: 50$ AM - 9:30 AM

$6: 45$ AM - 9:30 AM

$6: 50$ AM - 9:30 AM

LABORATORY LIMIT OF DETECTION
Abietic $\left(\mathrm{mg} / \mathrm{m}^{3}\right)$

1.16

*

0.04

0.08

1.32

0.07

1.7

0.20

0.44

0.42

2.6

0.45

0.49

1. $?$

0.27

1.7

2.3

0.5

0.03

0.62

0.43

0.20

0.18

0.1

$\mathrm{mg} / \mathrm{sample}$
Pimaric $\left(\mathrm{mg} / \mathrm{M}^{3}\right)$

$$
\begin{aligned}
& 0.08 \\
& \star \\
& 0.07 \\
& 0.01 \\
& 0.05 \\
& 0.08 \\
& 0.11 \\
& 0.02 \\
& 0.04 \\
& 0.09 \\
& 0.03 \\
& 0.03 \\
& 0.02 \\
& 0.08 \\
& 0.03 \\
& 0.13 \\
& 0.04 \\
& \star \\
& \star \\
& 0.02 \\
& 0.03 \\
& 0.04 \\
& 0.01
\end{aligned}
$$

0.1 $\mathrm{mg} / \mathrm{sample}$

* = below laboratory limit of detection 